Jurnal Ilmiah Magister Agribisnis, 2(1) 2020:53-59,
DoI:

\title{
Analisis Kelayakan Finansial Usaha Jeruk di Kabupaten Karo dan Kabupaten Langkat
}

\section{Financial Feasibility Analysis of Orange Business in Karo and Langkat Districts.}

\author{
Yodi Ermanto1), Yusniar Lubis²), Faoza Saragih ${ }^{3)}$ \\ 1) Program Studi Magister Agribisnis, Pascasarjana, Universitas Medan Area, Indonesia \\ 2) Magister Agribisnis, Pascasarjana, Universitas Medan Area, Indonesia \\ 3) Fakultas Pertanian, Universitas Samudra, Indonesia
}

\begin{abstract}
Abstrak
Penelitian ini bertujuan untuk mengetahui besar pendapatan dan kelayakan usahatani Jeruk di Kabupaten Karo dan Kabupaten Langkat. Penelitian ini dilakukan di Desa Bukit Mas Kecamatan Besitang dan di Desa Garingging Kecamatan Merek Kabupaten Karo, dilakukan secara purposive karena 2 (dua) daerah ini merupakan sentra penghasil Jeruk yang berbeda sistim panennya. Kabupaten Karo merupakan penghasil Jeruk Matang atau konsumsi langsung, sedangkan di Kabupaten Langkat bisa dipanen matang dan panen jus. Penelitian ini dilakukan dengan metode Simple Random Sampling dengan jumlah sampel yang diambil masing- masing 30 orang Petani yang sudah berpengalaman dibidang tanaman Jeruk. Pengambilan sampel dilakukan pada bulang April 2018. Metode yang analisis menggunakan perhitungan Net Present Value (NPV) dan B/C Rasio. Hasil penelitian menunjukkan bahwa usahatani jeruk di Kabupaten Karo dan Kabupaten Langkat secara finansial layak di usahakan karena dan terus dikembangkan merujuk pada perhitungan B/C rasio didapatkan kedua Kabupaten tersebut memiliki nilai lebih besar daripada 1, dimana Kabupaten Karo 3,13 \% dan Kabupaten Langkat 4,76\%. Katakunci : Kelayakan, Jeruk, NPV, B/C
\end{abstract}

\begin{abstract}
This study aims to determine the level of income and feasibility of farming orange in Karo and Langkat Districts. This research was conducted in the Bukit Mas Village in the Besitang District and in the Garingging Village in the Brand District of the Karo Regency. Karo Regency is a producer of Matang Oranges or direct consumption, while in Langkat Regency it can be harvested and juice harvested. This research was conducted by the method of Simple Random Sampling with the number of samples taken each 30 farmers who are experienced in the field of citrus plants. Sampling was carried out on April 2018. The method of analysis using the calculation of Net Present Value (NPV) and $B$ / C Ratio. The results showed that the citrus farming in Karo and Langkat Districts was financially feasible because and continued to be developed, referring to the $B$ / C ratio calculation obtained that the two regencies had values greater than 1, where Karo District was 3.13\% and Langkat District $4,76 \%$.

Keywords: Feasibility, Orange, NPV, B /C
\end{abstract}

How to Cite: Ermanto, Y., Y. Lubis, \& F. Saragih. (2020). Analisis Kelayakan Finansial Usaha Jeruk di Kabupaten Karo dan Kabupaten Langkat. Jurnal Ilmiah Magister Agribisnis, 2(1) 2020: 53-59,

*E-mail: Yusniar@uma.ac.id

ISSN 2550-1305 (Online)

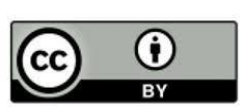


Ermanto, Y., Y. Lubis, \& F. Saragih. Analisis Kelayakan Finansial Usaha Jeruk di Kabupaten Karo dan Kabupaten Langkat.

\section{PENDAHULUAN}

Indonesia merupakan negara agraris yang memiliki potensi kekayaan alam dan keanekaragaman hayati yang luar biasa.Salah satu sektor yang sangat penting bagi Indonesia adalah sektor pertanian yang menjadi sektor unggulan dalam menggerakan roda perekonomian. Sektor ini pulalah yang mampu bertahan pada era krisis moneter, sementara sektor-sektor lain runtuh dan menurun.Disamping itu pula mayoritas penduduk Indonesia sebagian besar bekerja pada sektor pertanian dan menggantungkan hidupnya pada pertanian, oleh karena itu sektor pertanian menjadi sektor yang penting yang harus diperhatikan oleh pemerintah dalam perkembangan dan pertumbuhannya.

Dalam perjalanannya sektor pertanian telah berkontribusi nyata pada penyerapan tenaga kerja, sumber pendapatan, penyediaan bahan pangan, bahan baku industry, pakan dan bioenergy, sumber devisa negara, pembentukan capital juga usaha pelestarian lingkungan melalui praktek usaha tani yang ramah lingkungan. Dari beberapa sektor pertanian yang ada, selama ini sektor perkebunan menjadi sektor primadona, sejak tahun 2005 hingga tahun 2009 subsektor perkebunan merupakan satu-satunya subsektor yang mengalami surplus dengan menyumbang sebesar US\$ 17,63 milyar sedangkan subsektor lainnya yakni tanaman pangan, hortikultura, dan peternakan mengalami defisit. Pada tahun 2009 subsektor perkebunan hanya mencapai 17,9 persen namun pada tahun 2010 mengalami peningkatan menjadi 49,59 persen.

Salah satu komoditi hortikultura buah-buahan yang potensial untuk dibudidayakan adalah jeruk, dikarenakan jeruk sangat popular di tengah masyarakat luas baik sebagai buah di meja ataupun sari buah. Oleh karena itu di Indonesia, jeruk merupakan jenis buah konsumsi ketiga terbesar setelah pisang dan papaya dengan tingkat konsumsi sebanyak 1,2 kg/kapita/tahun. Beberapa jenis jeruk lokal yang dibudidayakan di Indonesia adalah jeruk Keprok (Citrus reticulata/nobilis L.), jeruk Siam (C. Microcarpa L. dan $C$. Sinesis. $L$ ) yang terdiri atas Siam Pontianak, Siam Garut, Siam Lumajang, jeruk manis (C. Auranticum L. dan C. Sinensis L.), jeruk sitrun/lemon (C. medica), dan jeruk besar (C. Maxima Herr.). Beberapa sentra produksi jeruk di Indonesia tersebar meliputi daerah Garut (Jawa Barat), Tawangmangu (Jawa Tengah), Batu (Jawa Timur), Tejakula (Bali), Selayar (Sulawesi Selatan), Pontianak (Kalimantan Barat), dan Medan (Sumatera Utara). Keberagaman jeruk tersebut memiliki kecocokan dengan masing-masing wilayah secara geografis. Perkebunan jeruk menjadi daya tarik tersendiri untuk petani-petani hortikultura buah-buahan. Dari potensi tersebut sehingga penelitian ini bertujuan untuk mengetahui kelayakan hortikultura buah jeruk di Kabupaten Langkat dan Karo.

\section{METODE PENELITIAN}

Penentuan lokasi penelitian dilakukan secara purposive sampling Desa Bukit Mas Kecamatan Besitang Kabupaten Langkat dan di DesaGaringgingKecamatan Merek Kabupaten Karo. Pemilihan lokasi di Kabupaten Langkat ini berdasarkan jumlah petani jeruk di desa ini merupakan terbesar dengan jumlah petani sebanyak 412 orang dan pemilihan lokasi di Desa Garingging Kecamatan Merek Kabupaten Karo merupakan salah satu desa penghasil jeruk berdasarkan informasi dari PPL Pertanian Kabupaten 
Karo.Waktu yang dibutuhkan untuk penelitian ini adalah 3 (tiga) bulan yaitu sejak bulan April sampai dengan Juni 2018.

Metode pengumpulan data dilakukan dengan metode survei. Data yang dikumpulkan berupa data primer dan data sekunder. Data primer berupa data penerimaan dan biaya - biaya yang dikeluarkan dalam usaha tani perkebunan jeruk dan yang dikumpulkan melalui wawancara langsung. Pengumpulan data primer di lokasi desa dilaksanakan melalui wawancara ke petani sampel. Untuk data sekunder desa diambil dari dari Kecamatan dan Kabupaten, pengumpulan data sekunder Kabupaten instansi terkait dan selanjutnya dilakukan verifikasi data. Data sekunder yang diambil berupa data keadaan umum dari lokasi survei.

Data dalam penelitian ini dijelaskan secara deskriptif kuantitatif, dianalisis menggunakan aplikasi komputer microsoft excel dan program SPSS, serta dikaji dengan menerapkan beberapa metode sebagai berikut.

Digunakan perhitungan Net Present value (NPV) dan B/C Ratio. Net Present Value merupakan pengukuran berapa nilai yang dihasilkan saat ini seandainya menanamkan sebuah investasi. NPV juga merupakan perbedaan di antara nilaipasar investasi dan biaya yang dikeluarkan. Discounted cash flow valuation adalah proses penilaian investasi melalui tingkat diskonto cash flow pada masa datang, untuk mengintepretasikan kelayakan suatu usaha dapat dilihat dari hasil perhitungan NPV. Jika nilai NPV positif maka investasi layak dilakukan, sebaliknya jika negatif maka investasi ditolak atau tidak layak. Menurut Sofyan (2002), NPV adalah nilai netto sekarang dari dana yang diinvestasikan selama umurproyek. NPV mencerminkan besarnya tingkat pengembalian dari usulan usaha atauproyek, oleh karena itu usulan proyek yang layak diterima haruslah memiliki nilai NPV >0, jika tidak maka proyek itu akan mengalami kerugian. Rumus yang digunakan dalam perhitungan net present value adalah sebagai berikut (Sofyan, 2002).

$$
N P V=\sum_{i=1}^{n} \frac{(B-C)}{(1+i)^{t}}
$$

\section{Dimana:}

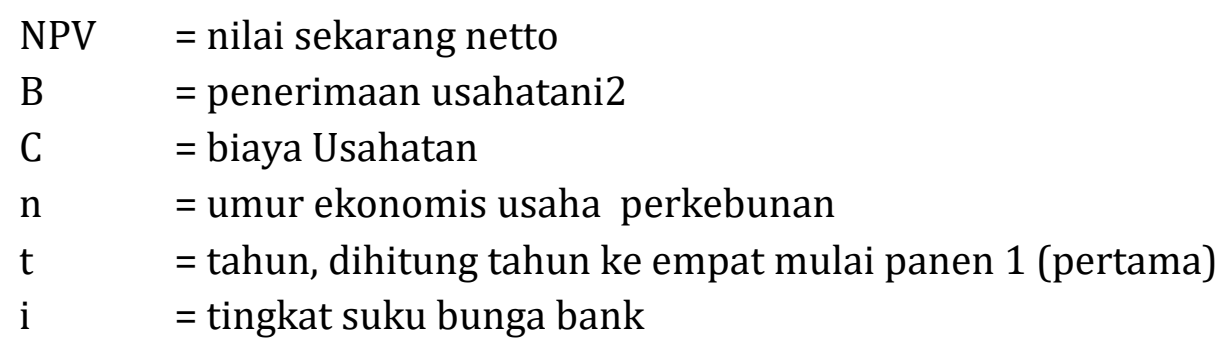

Kriteria untuk menerima dan menolak rencana investasi dengan metode NPV adalah sebagai berikut:

a. Apabila NPV > 0, maka usahatani layak,

b. Apabila NPV $<0$, maka usahatani tidak layak, dan

c. Apabila NPV $=0$, kemungkinan usahatani akan diterima atau di tolak, terserah kepada pengambil keputusan untuk dilaksanakan atau tidak. 
Ermanto, Y., Y. Lubis, \& F. Saragih. Analisis Kelayakan Finansial Usaha Jeruk di Kabupaten Karo dan Kabupaten Langkat.

\section{HASIL DAN PEMBAHASAN}

Petani jeruk yang menjadi sampel dalam penelitian ini sebanyak 60 orang sampel yang terdiri dari 30 sampel petani jeruk Kabupaten Karo dan 30 sampel petani jeruk Kabupaten Langkat. Berdasarkan hasil penelitian didapatkan bahwa usaha tani jeruk di Desa Bukit Mas Kecamatan Besitang Kabupaten Langkat telah berjalan selama kurang lebih selama 10 tahun setelah sebelumnya menanam kelapa sawit. Berikut adalah hasil produksi, harga dan penerimaan rata - rata selama satu tahun produksi usaha tani jeruk desa Bukit Mas.

Tabel 1. Rata - rata produksi dan penerimaan usahatani jeruk Desa Bukit Mas Kecamatan Besitang Kabupaten Langkat (Kg/Ha/Tahun)

\begin{tabular}{lll}
\hline Produksi $(\mathrm{Kg})$ & Harga $(\mathrm{Rp})$ & Penerimaan $(\mathrm{Rp} / \mathrm{Ha})$ \\
\hline 41.240 & 4.780 & 172.725 .700 \\
\hline
\end{tabular}

Sumber: Data Primer (diolah), 2018

Berdasarkan tabel 1 dapat diketahui bahwa produksi jeruk di Desa Bukit Mas Kecamatan Besitang Kabupaten Langkat sebanyak $41.240 \mathrm{Kg}$ per tahunnya. Adapun bentuk hasil yang dijual adalah jeruk peras yaitu kondisi jeruk yang belum cukup besar dan matang namun telah dapat di konsumsi. Petani jeruk di desa ini melakukan panen kurang lebih sebulan sekali sehingga selama setahun dapat menjual sebanyak 12 kali dengan rata - rata penjualan sebesar $3.437 \mathrm{Kg}$. Untuk harga jual jeruk peras bervariasi sekitar harga Rp. 4.500 - Rp. 5.000 / Kg dimana jeruk tersebut di ambil langsung oleh pedagang pengumpul.

Berdasarkan hasil penelitian didapatkan bahwa usaha tani jeruk di Desa Bukit Mas Kecamatan Secanggang Kabupaten Langkat telah berjalan selama kurang lebih selama 10 tahun setelah sebelumnya menanam kelapa sawit. Berikut adalah hasil produksi, harga dan penerimaan rata - rata selama satu tahun produksi usaha tani jeruk desa Bukit Mas

Tabel 2. Rata - rata produksi dan penerimaan usahatani jeruk Desa Garingging Kecamatan Merek Kabupaten Karo (Kg/Ha/Tahun)

\begin{tabular}{lll}
\hline Produksi $(\mathrm{Kg})$ & Harga $(\mathrm{Rp})$ & Penerimaan $(\mathrm{Rp} / \mathrm{Ha})$ \\
\hline 47.687 & 5.650 & 273.389 .833 \\
\hline
\end{tabular}

Sumber: Data Primer (diolah), 2018

Berdasarkan tabel 2 dapat diketahui bahwa produksi jeruk di Desa Garingging Kecamatan Merek Kabupaten Karo sebanyak 47.687 Kg per tahunnya. Adapun bentuk hasil yang dijual adalah jeruk manis yaitu kondisi jeruk yang telah cukup besar dan matang yang mempunyai rasa yang manis. Petani jeruk di desa ini melakukan panen selama setahun sebanyak 4 kali panen dengan jumlah per panen yaitu sebanyak 12.072 Kg. Untuk harga jual jeruk peras bervariasi sekitar harga Rp. 5.000 - Rp. 7.000 / Kg dimana jeruk tersebut di ambil langsung oleh pedagang pengumpul untuk kemudian dipasarkan baik ke daerah Sumatera Utara maupun ke Jakarta. 
Perhitungan kelayakan usahatani jeruk dengan metode perhitungan Net Present Value (NPV) dan B/C Ratio. Berikut adalah hasil perhitungan kelayakan usaha tani jeruk di Kabupaten Langkat dan Kabupaten Karo.

Tabel 3. Hasil Penilaian Kelayakan Usaha Tani Jeruk

\begin{tabular}{clrr}
\hline No & Keterangan & UT Jeruk Langkat (Rp) & UT Jeruk Karo (Rp) \\
\hline 1 & Net Present Value & $456.395 .735,63$ & $627.724 .420,23$ \\
2 & B/C Ratio & 4,76 & 3,13 \\
\hline
\end{tabular}

Sumber: Data Primer (diolah), 2018

Kelayakan finansial usaha tani jeruk di Kabupaten Langkat dan Kabupaten Karo dengan menggunakan Net Present Value (NPV) dan B/C Ratio maka dapat disimpulkan keduanya layak. Hal ini ditunjukkan dengan nilai NPV yang positif dan nilai B/C ratio yang lebih besar daripada 1 pada tabel 3.

\section{Hasil Perhitungan Uji Beda Rata-Rata}

Dalam penelitian ini telah dilakukan Uji Beda Rata-Rata terhadap pendapatan usaha tani jeruk. Berikut adalah hasil Uji Beda Rata-Rata terhadap pendapatan usahatani jeruk di Kabupaten Langkat dan Kabupaten Karo

Tabel 4. Hasil Uji Beda Rata - Rata

\begin{tabular}{lr}
\hline & Pendapatan \\
\hline Mann-Whitney U & 144.000 \\
Wilcoxon W & 609.000 \\
Z & -4.524 \\
Asymp. Sig. (2-tailed) & .000 \\
\hline
\end{tabular}

Sumber: Data Primer (diolah), 2018

Berdasarkan tabel diatas dapat dilihat bahwa nilai signifikansi yang diperoleh adalah 0,000 dimana nilai yang diperoleh lebih kecil dari pada dinilai alpha yang ditentukan sebesar 5 persen atau 0,05 . Hal ini menunjukkan bahwasanya $\mathrm{H}_{0}$ ditolak dan $\mathrm{H}_{1}$ diterima yang artinya terdapat perbedaan pendapatan usaha tani jeruk di Kabupaten Langkat dan Kabupaten Karo .

\section{Uji Beda Rata - Rata}

Berdasarkan hasil uji beda rata - rata maka diketahui bahwa terdapat perbedaan pendapatan yang signifikan antara petani di Kabupaten Karo dan petani di Kabupaten Langkat. Berikut adalah data penerimaan dan biaya usaha tani jeruk.

Dari tabel 5 dapat dilihat bahwasanya rata-rata total pendapatan yang diterima petani di Kabupaten Langkat dan Kabupaten karo memiliki selisih sebesar Rp. 51.441.728,- dan biaya yang dikeluarkan oleh petani di Kabupaten Karo dua lebih besar 
bila dibandingkan dengan petani di Kabupaten Langkat yang disebabkan penggunaan saprodi pada usaha taninya yang memiliki harga yang lebih mahal seperti harga pupuk di Kabupaten Langkat lebih murah dikarenakan adanya pupuk subsidi dan jenis pupuk yang digunakan hanya empat jenis sedangkan di Kabupaten karo ada lima jenis pupuk. Begitu juga dengan harga dan jumlah jenis pestisida yang digunakan di Kabupaten Karo lebih mahal dan lebih banyak.Walau pada rata-rata total penerimaan di Kabupaten Karo lebih besar yang disebabkan jumlah produksi yang lebih besar dan harga jual yang lebih tinggi dikarenakan jumlah berat yang dihasilkan pada jeruk karo lebih besar bila dibandingkan dengan jeruk langkat.Namun frekuensi panen jeruk langkat lebih banyak yaitu sebanyak 12 kali setahun sedangkan jeruk karo hanya 4 kali setahun.

Tabel 5. Rata- Rata Pendapatan Usaha Tani Jeruk

\begin{tabular}{|c|c|c|c|}
\hline No & Keterangan & $\begin{array}{l}\text { Kabupaten Langkat } \\
\text { (Rp) }\end{array}$ & $\begin{array}{c}\text { Kabupaten Karo } \\
\text { (Rp) }\end{array}$ \\
\hline 1 & Total Penerimaan & 172.725 .000 & 273.389 .833 \\
\hline 2 & Total Biaya & 35.671 .867 & 84.894 .972 \\
\hline 3 & Total Pendapatan & 137.053 .133 & 188.494 .861 \\
\hline
\end{tabular}

Sumber: Data Primer (diolah), 2018

\section{SIMPULAN}

Diketahui bahwa usaha tani jeruk di Desa Bukit Mas Kecamatan Besitang Kabupaten Langkat berdasarkan nilai NPV. Diketahui bahwa usaha tani jeruk di Desa Garingging Kecamatan Merek Kabupaten Karo layak. Berdasarkan hasil uji beda rata-rata diketahui bahwa pendapatan usaha tani jeruk di Desa Bukit Mas Kecamatan Besitang Kabupaten Langkatdan DesaGaringging Kecamatan Merek Kabupaten Karo, berbeda signifikan. Usaha tani jeruk yang paling layak untuk diusahakan dan dikembangkan adalah usaha tani jeruk di Desa Bukit Mas, Kecamatan Secanggang, Kabupaten Langkat.

Diharapkan kepada petani jeruk di Desa Garingging Kecamatan Merek Kabupaten Karo untuk lebih mengefisienkan usaha tani jeruknya sehingga dapat meningkatkan pendapatannya. Kepada petani jeruk di Desa Bukit Mas Kecamatan Besitang Kabupaten Langkat agar dapat menjual hasil akhir produknya menjadi produk jeruk manis agar mendapatkan harga jual yang tinggi.

\section{DAFTAR PUSTAKA}

AAK. (1994). Budidaya Tanaman Jeruk. Kansius :Yogyakarta.

BPS. (2016). Sumatera Utara Dalam Angka 2016. Medan

Gittinger, J.P. (1986). Analisa Ekonomi Proyek-Proyek Pertanian. Terjemahan. Edisi Kedua. UI-Press dan John Hopkins. Jakarta.

Hernanto, F. (1991). Ilmu Usahatani. PT. Penebar Swadaya.Jakarta

Indonesia Horticulture Investment \& Business Forum. (2013).Temukan Kiat Berinvestasi dan Berbisnis Hortikultura.Indonesia Horticulture Investment \& Business Forum. Bogor.

Joesoef, M. (1993). Penutun Berkebun Jeruk. Bhratara K arya Aksara : Jakarta.

Kasmir dan Jakfar. (2003). Studi Kelayakan Bisnis. Penerbit Kencana Prenada Media, Jakarta

Musa, Ali. (2012). Perencanaan dan Evaluasi Proyek Agribisnis Konsep dan Aplikasi. Penerbit ANDI. Yogyakarta

Putong, Iskandar. (2005). Teori Ekonomi Mikro. Penerbit Mitra Wacana Media. Jakarta 
Rahardja, Pratama dan Mandala. (2006). Teori Ekonomi Mikro Suatu Pengantar. Lembaga Penerbit FE UI, Jakarta

Rismunandar.(1986). Bercocok Tanaman Jeruk. Sinar Baru : Bandung

Sarwono. (1994). Bubiaya Tanaman Jeruk. Bumi Aksara : Jakarta.

Soekartawi. (1995). Analisis Usahatani. UI Press. Jakarta . (2002). Analisis Usahatani. UI Press. Jakarta

Soekartawi, dkk.(2011).Ilmu Usahatani dan Penelitian Untuk Pengembangan Petani Kecil. UI-Press, Jakarta Soelarso, R. Bambang. (1996). Budidaya Jeruk Bebas Penyakit. Kansius: Yogyakarta.

Soepomo. (1997). Metode Penelitian. Ghalia Indonesia, Bogor

Sofyan. S. Harahap. (2002). Teori Akuntansi. Edisi Revisi. PT. Raja Grafindo Persada. Jakarta

Sugiarto. (2002). Ekonomi Mikro Sebuah Kajian Komprehensif. Gramedia Pustaka Utama, Jakarta

Suratiyah, Ken. (2009). Ilmu Usahatani. Penebar Swadaya, Jakarta. 